\title{
Still No Substantial Evidence to Use Prophylactic Antibiotic at Operative Vaginal Delivery: Systematic Review and Meta-Analysis
}

\author{
Yifru Berhan (D), Sisay Kirba, and Achamyelesh Gebre \\ St. Paul's Hospital Millennium Medical College, Addis Ababa, Ethiopia \\ Correspondence should be addressed to Yifru Berhan; yifrub@yahoo.com
}

Received 7 November 2019; Accepted 1 May 2020; Published 19 May 2020

Academic Editor: Curt W. Burger

Copyright ( $\odot 2020$ Yifru Berhan et al. This is an open access article distributed under the Creative Commons Attribution License, which permits unrestricted use, distribution, and reproduction in any medium, provided the original work is properly cited.

\begin{abstract}
Background. Postpartum maternal infection is still a common problem worldwide, mainly due to obstetric risk factors. The use of prophylactic antibiotic at operative vaginal delivery (OVD), taking it as a standalone risk factor, has been controversial. The purpose of this review was to rigorously evaluate the association of OVD with postpartum infection and shed light on such highly controversial issue. Methods. A computer-based literature search was done mainly in the databases of PUBMED, HINARI health research, and the Cochrane library. Systematic review and meta-analysis were done by including 14 articles published between 1990 and August 2019. Results. The average absolute risk of postpartum infection at OVD from seven large cohort studies was $1 \%$. Few studies showed a weak association of OVD with postpartum infection without being adjusted to perineal wound, but the pooled meta-analysis showed statistically significant association with non-OVD. In the included randomized trial, 97\% of the study participants had perineal wound for whom repairs were performed; the risks of maternal infection and perineal wound breakdown were comparable, and maternal infections other than perineal wound infection did not show significant difference between prophylactic antibiotic and placebo groups. The majority of included studies demonstrated a strong association of postpartum infection and perineal wound dehiscence with episiotomy and perineal tear. Conclusion. Both the relative and absolute risks of postpartum infection at OVD are extremely low unless accompanied by episiotomy and $3^{\text {rd }} / 4^{\text {th }} \mathrm{t} \mathrm{degree} \mathrm{perineal}$ tear. From previous studies, there is no substantial evidence to use prophylactic antibiotic at OVD, but episiotomy and perineal tear.
\end{abstract}

\section{Introduction}

Postpartum maternal infection is still a common problem worldwide, but the exact incidence is unknown because of the occurrence of the majority of infections after discharge from a health facility $[1,2]$. Depending on the underlying risk factor, the quality of obstetric care, and the region where the women live in, postpartum infection may complicate $1 \%$ to $4 \%$ of vaginal and $5 \%$ to $20 \%$ of caesarean deliveries $[1,3-5]$. A large body of evidence demonstrated that the single most important risk factor for postpartum infection is caesarean section (CS) [6].

There are several other risk factors associated with postpartum infection (like bacterial vaginosis, prolonged rupture of membranes, chorioamnionitis, and manual removal of the placenta), for which antibiotic administration is important, but the use of prophylactic antibiotic at operative vaginal delivery (OVD), taking it as a standalone risk factor, has been very controversial for decades. The controversy is with regard to the difference in potential risk abdominal and vaginal operative deliveries incurring to postpartum infection.

Traumatic or surgical wound in the genital tract and perineum increases the risk of postpartum infection, which is again the common cause for wound infection and dehiscence [7]. The higher risk of postpartum infection (endometritis in particular) in women with CS is also mainly due to the surgical entry into the endometrial cavity. Similarly, since performing episiotomy and sustaining trauma to the genital tract and perineum during OVD are common, there is a tendency to associate the increased risk of postpartum infection with OVD. Taking the less presumed risk, 
many used to disagree with the routine administration of antibiotic prophylaxis at OVD. Among others, the World Health Organization (WHO) and many national guidelines are not recommending prophylactic antibiotic at OVD [8-11].

The argument is that repaired episiotomy or perineal tear wound infection and dehiscence is due to the surgical and traumatic wound, not merely by the applied instruments. In contrast, all CSs cause surgical wound to the uterus and abdominal wall, but all OVDs are not conducted with episiotomy and do not always cause trauma to the genital tract and perineum. The significant reduction of perineal surgical wound infection with prophylactic antibiotic is also an indirect evidence for the increased risk of infection in women with perineal wound $[6,12]$.

In general, there is a paucity of data on the importance of prophylactic antibiotics at OVD. The first randomized clinical trial was done in 1989 with small sample size (393 study participants) for which the updated Cochrane review in 2017 concluded that the data were inadequate to make conclusion [13].

The second randomized clinical trial was reported in May 2019 and made a firm conclusion on the importance of prophylactic antibiotic at OVD [14] and got much of the media attention, but the strength of the evidence for that purpose is questionable. The few observational studies that reported the risk of postpartum infection in relation to OVD were not reviewed from the perspective of the contribution of perineal wound to postpartum infection. Therefore, the purpose of this review was to rigorously evaluate the association of OVD with postpartum infection as a standalone risk factor and shed light on such highly controversial issue.

\section{Methods}

2.1. Search Strategy. A computer-based literature search was done in the databases of Medline/PUBMED, HINARI health research, and the Cochrane library. Further search was conducted using Google scholar search engine and from the reference lists of retrieved articles. The search terms were as follows: operative vaginal delivery, instrumental vaginal delivery, forceps assisted delivery, vacuum assisted delivery, obstetric forceps, vacuum extractor, ventouse assisted delivery, antibiotic prophylaxis, postpartum infection (as listed below), maternal sepsis, puerperal sepsis, perineal wound infection, perineal tear, perineal wound, perineal wound dehiscence, and episiotomy. Boolean logic (and/or) was applied during searching by combining the search terms alternatively.

2.2. Study Selection and Inclusion Criteria. In this review, the literature search was done independently by two authors (YB and SK) using the selected search terms. When there was a discrepancy in individually selected studies, it was resolved by discussion and by reviewing those specific studies in detail, together with the third author. The predetermined inclusion criteria were studies that (1) compared the risk of postpartum infection with or without antibiotic prophylaxis in instrument assisted vaginal deliveries, (2) reported the magnitude of postpartum infection among women for whom vacuum or forceps or both applied, (3) were written in English, and (4) were published between 1990 and August 2019. Some of the studies were included only for their descriptive data.

2.3. Data Extraction. Many of the included studies reported several other relevant data. Since the interest of this review was on the potential risk of OVD to postpartum infection and the place of prophylactic antibiotic for it, the abstracted data were limited to those variables. Standard Excel spreadsheet was used to extract the required data from selected individual studies. The following data were extracted from the selected studies: name of authors, study period, study design, study location, study population/ sample size, risk factors, statistical analysis, postpartum infections cross tabulated with prophylactic antibiotic, OVD, forceps or vacuum delivery, and episiotomy and/or perineal tear.

2.4. Study Quality Assessment. The risk of bias in the randomized clinical trial [14] was assessed using the Cochrane tool. STROBS (Strengthening the Reporting of Observational Studies) checklist, as recommended by the WHO [15], was used to assess the risk of bias in the included observational studies. Starting from the title and abstract to the discussion section, an assessment was made with 21 defined items. In their introduction section, the rationale and study objective, in their methods section (as summarized in Table 1), the study population/sample size, study design, study period, outcome measures and statistical methods were described. In the results section, the descriptive data, outcome, and the main results were assessed. In the discussion section, the descriptive data of all and conclusions drawn from them are appropriate. However, we have identified that the analytical part specific to the variables we were interested in was not correct in three studies as described in our results section. The clinical trial was not rigorously analyzed using multivariate logistic regression.

2.5. Operational Definition. In this review, postpartum infection defining terminologies were perineal infection, maternal sepsis, surgical or traumatic wound infection, endometritis, urinary tract infection, too painful perineum, postpartum fever, septic pelvic thrombophlebitis, and peritonitis and mastitis after delivery within 6 -week period. OVD reported as obstetric forceps or vacuum assisted vaginal delivery or trial was included. In this review, postpartum infection and maternal infection are interchangeably used.

2.6. Data Analysis and Presentation. The summary of the included studies, pertinent to the study's objective, is presented, highlighting the major findings and identifying risk factors for postpartum infection. Some data reported in tabular form for a different dependent variable are converted to bar graphs to show the absolute and relative risks of OVD for postpartum 
TABLE 1: General characteristics of the included studies in relation to postpartum infection.

\begin{tabular}{|c|c|c|c|c|c|}
\hline $\begin{array}{l}\text { Authors/study period/ } \\
\text { country }\end{array}$ & Study design & $\begin{array}{c}\text { Study } \\
\text { population }\end{array}$ & $\begin{array}{l}\text { Risk of postpartum } \\
\text { infection }\end{array}$ & Risk factors attributed & $\begin{array}{c}\text { Statistical } \\
\text { analysis done for }\end{array}$ \\
\hline $\begin{array}{l}\text { Knight et al./March 13, } \\
\text { 2016-June 13, 2018, UK }\end{array}$ & $\begin{array}{l}\text { Multicenter } \\
\text { randomized } \\
\text { clinical trial }\end{array}$ & $\begin{array}{l}1715 \text { trial and } \\
1705 \text { placebo } \\
\text { group }\end{array}$ & $\begin{array}{l}11 \% \text { trial group and } \\
18 \% \text { placebo group }\end{array}$ & $\begin{array}{l}\text { Operative vaginal deliveries } \\
\text { (OVD) (forceps and vacuum) }\end{array}$ & $\begin{array}{l}\text { Unadjusted risk } \\
\text { ratio with } 95 \% \\
\text { CI } \\
\end{array}$ \\
\hline $\begin{array}{l}\text { Acosta et al./1986-2009 } \\
\text { (study 1), Scotland }\end{array}$ & Case-control & $\begin{array}{l}103 \text { cases and } \\
412 \text { controls }\end{array}$ & Not reported & $\begin{array}{c}\text { Obesity, age }<25 \text { years, OVD, } \\
\text { multiparity, anemia, labor } \\
\text { induction, CS, and preterm }\end{array}$ & $\begin{array}{l}\text { AOR with } 95 \% \\
\text { CI }\end{array}$ \\
\hline $\begin{array}{l}\text { Acosta et al./June 1, } \\
\text { 2011-May 31, } 2012 \\
\text { (study 2), UK }\end{array}$ & Case-control & $\begin{array}{l}365 \text { cases and } \\
757 \text { controls }\end{array}$ & $\begin{array}{c}\text { Incidence of severe } \\
\text { sepsis, } 4.7 \text { per } 10,000 \\
\text { maternities }\end{array}$ & $\begin{array}{l}\text { Black or other ethnic } \\
\text { minority, primiparous, } \\
\text { preexisting illness, or on } \\
\text { antibiotics, OVD, and CS }\end{array}$ & $\begin{array}{l}\text { AOR with } 95 \% \\
\text { CI }\end{array}$ \\
\hline $\begin{array}{l}\text { Acosta et al./2005-2007 } \\
\text { (study 3), USA }\end{array}$ & $\begin{array}{l}\text { Retrospective } \\
\text { cohort }\end{array}$ & $\begin{array}{l}1598 \text { women } \\
\text { with sepsis }\end{array}$ & $\begin{array}{c}\text { Incidence of all } \\
\text { sepsis, } 10 \text { per } 10,000 \\
\text { live births }\end{array}$ & $\begin{array}{l}\text { PPH, hypertension, multiple } \\
\text { birth, primiparous, black }\end{array}$ & $\begin{array}{l}\text { AOR with } 95 \% \\
\text { CI }\end{array}$ \\
\hline $\begin{array}{l}\text { Macleod et al./Oct } \\
\text { 2004-Aug 2006/UK }\end{array}$ & $\begin{array}{l}\text { Prospective } \\
\text { cohort }\end{array}$ & 1366 & $\begin{array}{c}\text { Perineal infection in } \\
\text { episiotomy group } \\
5.1 \%\end{array}$ & $\begin{array}{l}\text { Vacuum and forceps delivery } \\
\text { with episiotomy }\end{array}$ & $\begin{array}{l}\text { AOR with } 95 \% \\
\text { CI }\end{array}$ \\
\hline $\begin{array}{l}\text { Kabiru et al./1980-1996/ } \\
\text { USA }\end{array}$ & $\begin{array}{l}\text { Retrospective } \\
\text { cohort }\end{array}$ & 6882 & $2.9 \%$ & Not reported & $\begin{array}{c}\text { Unadjusted } \\
\text { relative risk with } \\
95 \% \text { CI }\end{array}$ \\
\hline $\begin{array}{l}\text { Bailit et al./2008-2011/ } \\
\text { USA }\end{array}$ & $\begin{array}{c}\text { Retrospective } \\
\text { cohort }\end{array}$ & 2531 & $\begin{array}{c}0.5 \% \text { with OVD and } \\
5.3 \% \text { with CS } \\
\end{array}$ & Strongly CS, weakly OVD & $\begin{array}{l}\text { AOR with } 95 \% \\
\text { CI }\end{array}$ \\
\hline $\begin{array}{l}\text { Muraca et al./2003-2013/ } \\
\text { Canada }^{\dagger}\end{array}$ & $\begin{array}{c}\text { Retrospective } \\
\text { cohort }\end{array}$ & $\begin{array}{c}8184 \text { OVD, } \\
9300 \mathrm{CS}\end{array}$ & $\begin{array}{c}0.8 \% \text { with OVD and } \\
1.4 \% \text { with CS }\end{array}$ & CS & $\begin{array}{l}\text { AOR with } 95 \% \\
\text { CI }\end{array}$ \\
\hline $\begin{array}{l}\text { Muraca et al./2003-2013/ } \\
\text { Canada }^{\ddagger}\end{array}$ & $\begin{array}{c}\text { Retrospective } \\
\text { cohort }\end{array}$ & $\begin{array}{c}5705 \text { OVD } \\
5734 \mathrm{CS} \\
\end{array}$ & $\begin{array}{c}0.9 \% \text { with OVD and } \\
2.0 \% \text { with CS } \\
\end{array}$ & CS & $\begin{array}{l}\text { AOR with } 95 \% \\
\text { CI }\end{array}$ \\
\hline Son et al./4 years/USA & $\begin{array}{l}\text { Retrospective } \\
\text { analysis }\end{array}$ & $\begin{array}{l}945 \text { OVD, } 285 \\
\text { repeat CS }\end{array}$ & $\begin{array}{c}\text { Endometritis: } 2.5 \% \\
\text { with OVD and } 9.1 \% \\
\text { with CS } \\
\end{array}$ & CS & $\begin{array}{l}\text { AOR with } 95 \% \\
\text { CI }\end{array}$ \\
\hline $\begin{array}{l}\text { Ducarme et al./Dec } \\
\text { 2008-Oct2013/France }\end{array}$ & $\begin{array}{c}\text { Prospective } \\
\text { cohort }\end{array}$ & 2138 & $1.4 \%$ & $\begin{array}{c}\text { Not tested specific to } \\
\text { maternal infection }\end{array}$ & NA \\
\hline $\begin{array}{l}\text { Gommesen et al./Jul } \\
\text { 2015-Jan 2018/Denmark }\end{array}$ & $\begin{array}{l}\text { Prospective } \\
\text { cohort }\end{array}$ & 400 & $\begin{array}{l}\text { Infection: } 5.8 \% \text {; } \\
\text { perineal wound } \\
\text { dehiscence: } 15.3 \%\end{array}$ & Episiotomy and obesity & $\begin{array}{l}\text { AOR with } 95 \% \\
\text { CI }\end{array}$ \\
\hline $\begin{array}{l}\text { Axelsson et al./ } \\
\text { 2005-2012/Sweden }\end{array}$ & $\begin{array}{l}\text { Retrospective } \\
\text { cohort }\end{array}$ & 5,991 & $\begin{array}{l}\text { Overall infection: } \\
11.7 \%\end{array}$ & $\begin{array}{c}\text { CS, perineal tear, episiotomy, } \\
\text { anemia, placenta removal, } \\
\text { OVD }\end{array}$ & $\begin{array}{l}\text { AOR with } 95 \% \\
\text { CI }\end{array}$ \\
\hline $\begin{array}{l}\text { Lydon-Rochelle et al./ } \\
\text { 1987-1996/USA }\end{array}$ & $\begin{array}{c}\text { Retrospective } \\
\text { cohort }\end{array}$ & 256,795 & $\begin{array}{c}\text { Overall uterine } \\
\text { infection rate: } 3.5 \%\end{array}$ & Strongly CS, weakly OVD & $\begin{array}{l}\text { AOR with } 95 \% \\
\text { CI }\end{array}$ \\
\hline $\begin{array}{l}\text { Liyu et al./1997-2001/ } \\
\text { Canada }\end{array}$ & $\begin{array}{c}\text { Retrospective } \\
\text { cohort }\end{array}$ & 900,108 & $\begin{array}{c}\text { Major puerperal } \\
\text { infection: } 0.3 \%\end{array}$ & $\begin{array}{l}\text { Weakly with vacuum and a bit } \\
\text { strongly with forceps and CS }\end{array}$ & $\begin{array}{l}\text { AOR with } 95 \% \\
\text { CI }\end{array}$ \\
\hline
\end{tabular}

${ }^{\dagger}$ Women with dystocia and prolonged second stage; ${ }^{*}$ women with fetal distress and prolonged second stage.

infection with other modes of delivery, including accompanied episiotomy and/or $3^{\text {rd }} / 4^{\text {th }}$ degree perineal tears.

Some additional bivariate analyses were done for the randomized clinical trial study taking the presented data to show the relative risk of postpartum infection and wound dehiscence comparing perineal wound infection and dehiscence with other types of maternal infection. One more bivariate analysis was done using the Acosta et al. study data [16] to show the statistically significant association of episiotomy with perineal infection.

Subgroup meta-analysis was done using OpenMetaanalyst software for Windows 10 (64-bit) to assess the odds ratios (OR) of OVD for postpartum infection in comparison with spontaneous vaginal delivery (SVD) and CS.
The contribution of OVD among women who developed postpartum infection was also determined in the metaanalysis. Since there is significant heterogeneity among included studies, the random effect model was used. Included studies' heterogeneity was assessed by computing values for $I^{2}$ and $P$ values. The OR and 95\% confidence intervals were computed with the DerSimonian-Laird method. Three-digit fraction numbers were approximated to two-digit numbers.

\section{Results}

As presented in Figure 1 (PRISMA flow chart), 14 articles were eligible for this review [2, 7, 14, 16-26]. One clinical trial and 13 observational studies (2 case-control and 11 


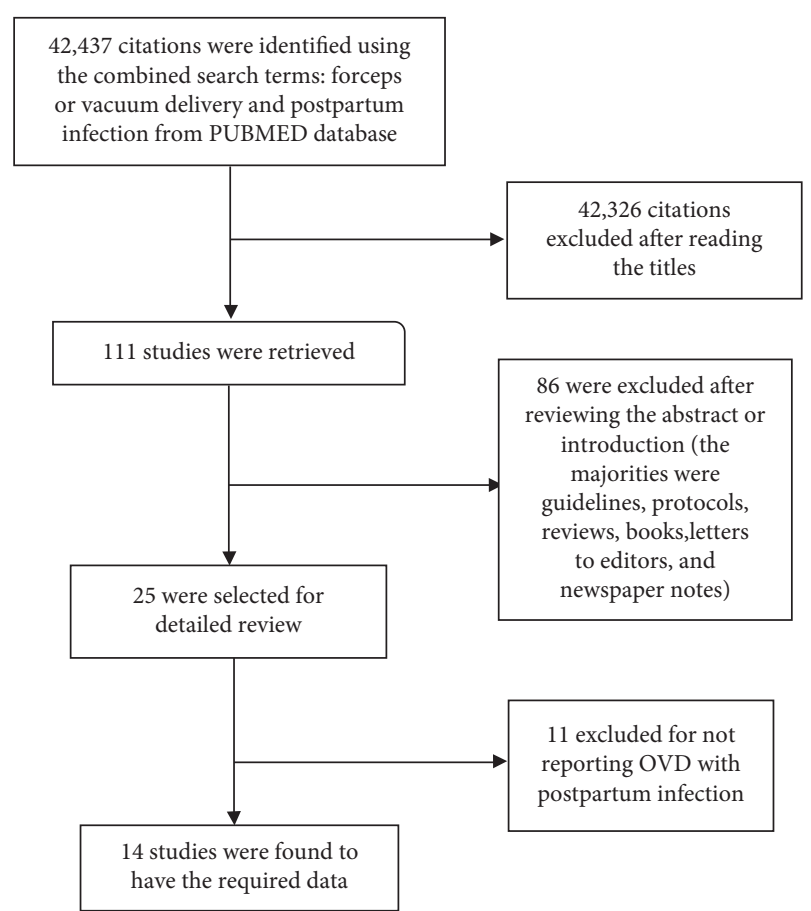

FIgURE 1: Flow diagram showing the selection process of the included studies (PRISMA).

cohort) were included (Table 1). All were from Western developed countries, predominantly from the United States of America and United Kingdom. The study populations in the majority of these studies (in the interest of this review) were in thousands, ranging from 400 to 65,991 .

The risk of postpartum infection ranges from $0.1 \%$ to $18 \%$. CS, episiotomy, and perineal tear were identified as a major risk factor for postpartum infection in the majority of the included studies. Nine studies performed logistic regression and determined the adjusted odds ratio; however, as described below, the major confounders (at least episiotomy and perineal tear) were not included in the adjusted analysis. The instrumental interventions were reported as forceps/ vacuum trial [21, 22], applied [24], or delivery [19, 20].

Table 2 summarizes the association of maternal infection with OVD in the antibiotic prophylaxis and placebo groups [14]. This study was a multicenter randomized controlled trial with large sample size (1715 in the amoxicillin and clavulanic acid group and 1705 in the placebo group) aiming to investigate the efficacy of antibiotic prophylaxis in preventing maternal infection after OVD. In the original study, for the primary outcome variable (antibiotic prescription for confirmed or suspected maternal infection within 6 weeks of delivery, including perineal wound infection, endomyometritis, urinary tract infection, pyelonephritis, bacteremia, and sepsis), unadjusted risk ratios with 95\% CI were determined.

It was reported that in $89 \%$ of the included study participants, episiotomies were performed. There were 1053 (31\%) perineal tears (266 isolated and 787 with episiotomy). Overall, 97\% (3310/3420) of the study participants had perineal wound for whom repairs were performed for almost all. Among women for whom episiotomy was done and/or who experienced perineal tear, 13.6\% (414/3044) developed wound breakdown. Perineal wound sutured was the base for determining the isolated perineal tear $(1645-1519=126$; $1665-1525=140)$. Thus, the difference between the total and isolated perineal tears $(493-126=367 ; 560-140=420)$ was the double perineal wound (episiotomy + perineal tear).

The risk of wound breakdown in the intervention and placebo group was $142(11 \%)$ and $272(21 \%)$, respectively. Interestingly, the proportion of this result was almost comparable with the risk of maternal infection in the intervention and placebo group, $180(11 \%)$ and $306(18 \%)$, respectively. With regard to the absolute risk, assuming that all wound breakdowns were due to infection, the remaining 38 (2.9\%) maternal infections in the intervention group and $34(2.6 \%)$ maternal infections in the placebo group were some other infections as listed as primary outcome indicators and were comparable. The absolute risk of ever too painful perineum in the antibiotic group was also comparable with an absolute risk of wound breakdown and overall maternal infection (11\% each).

As a result, three variables (maternal infection other than perineal wound infection, maternal infection other than wound breakdown, and endometritis) did not show statistically significant difference between the antibiotic and placebo groups. The perineal wound infections accounted for $62 \%(111 / 180)$ of antibiotic group and $73 \%(222 / 306)$ of the placebo group. The implication is that the statistically significant difference between the antibiotic and placebo groups was because of the perineal wound infection. The absolute risk of perineal infection was incomparably higher than other types of maternal infections, including endometritis.

As shown in Figure 2, the relative risk of maternal sepsis and perineal infections was much lower in OVD as compared with other modes of delivery [19]. The relative risk of uncomplicated sepsis in OVD was about 14-fold, 8-fold, and 4 -fold lower than SVD and primary and repeat CS, respectively. Similarly, the relative risks of severe sepsis and septic shock in OVD were much lower than other modes of delivery, which were highly statistically significant.

The absolute risk of perineal infection in forceps or vacuum delivery with episiotomy was more than 3.6-fold higher $(5.1 \%$ vs $1.4 \%)$ than OVD conducted without episiotomy (Figure 3). The relative risk of perineal infection with episiotomy was also highly significant (odds ratios (OR) for vacuum and forceps were 2.9 and 5.2 , respectively; $P$ value of the overall $=0.002$ ) $[16]$.

As the different large sample size study reports are summarized in Figure 4, the absolute risk of developing postpartum infection was even much lower than the above reports (the majority of total OVD related postpartum infection ranging from $0.1 \%$ to $0.5 \%$, and the highest was $3.3 \%$ ), with an average of $1 \%$ of the included studies in the graph [19-22, 24-26]. In Ducarme et al.'s study [23], the risk of postpartum endometritis was compared between OVD and repeat CS without OVD attempt. The risk of endometritis at OVD was by more than 3.6-fold less common than CS. 
TABLE 2: Obstetric procedures and traumatic and infectious complications (redeveloped from the original study by Knight et al. with some additional variables and analysis).

\begin{tabular}{|c|c|c|c|}
\hline Procedures and complications & $\begin{array}{l}\text { Antibiotic trial group }(n=1715) \text {, no } \\
(\%)\end{array}$ & $\begin{array}{c}\text { Placebo group }(n=1705) \text {, no } \\
(\%)\end{array}$ & $P$ value \\
\hline Episiotomy (total) & $1519(89.0)$ & $1525(89.0)$ & 0.2 \\
\hline Perineal tear (total) & $493(29.0)$ & $560(33.0)$ & 0.004 \\
\hline Isolated perineal tear & $126(7.0)$ & $140(8.0)$ & 0.2 \\
\hline Perineal tear and episiotomy & $367(21.0)$ & $420(25.0)$ & 0.01 \\
\hline Sutured perineal wound & $1645(99.0)^{*}$ & $1665(100.0)^{*}$ & NA \\
\hline Confirmed or suspected maternal infection & $180(11.0)$ & $306(18.0)^{\ddagger}$ & $<0.0001$ \\
\hline Perineal wound infection & $111(7.0)$ & $222(13.0)$ & $<0.0001$ \\
\hline $\begin{array}{l}\text { Maternal infection other than perineal wound } \\
\text { infection }\end{array}$ & $69(4.0)$ & $84(5.0 \%)$ & 0.1 \\
\hline Wound breakdown ${ }^{\dagger}$ & $142(11.0)$ & $272(21.0)$ & $<0.0001$ \\
\hline Maternal infection other than wound breakdown & $38(2.0)$ & $34(2.0)$ & 0.2 \\
\hline Endometritis & $15(1.0)$ & $23(1.0)$ & 0.2 \\
\hline Ever too painful perineum $^{\dagger}$ & $136(11.0)$ & $198(15.0)^{*}$ & $<0.00025$ \\
\hline
\end{tabular}

${ }^{\dagger}$ The denominator for antibiotic trial and placebo groups is 1296 and 1297, respectively. ${ }^{*}$ The percentage in the original study for two variables in the placebo group ("confirmed or suspected maternal infection" and "ever too painful perineum") was reported as $19 \%$ and $17 \%$, respectively. We thought that as a typographic error and made corrections. *The "missing" cases (54 for antibiotic trial group and 33 for the placebo group) were included in numerator in the original study report to determine the proportion, giving $99 \%$ and $100 \%$, respectively.

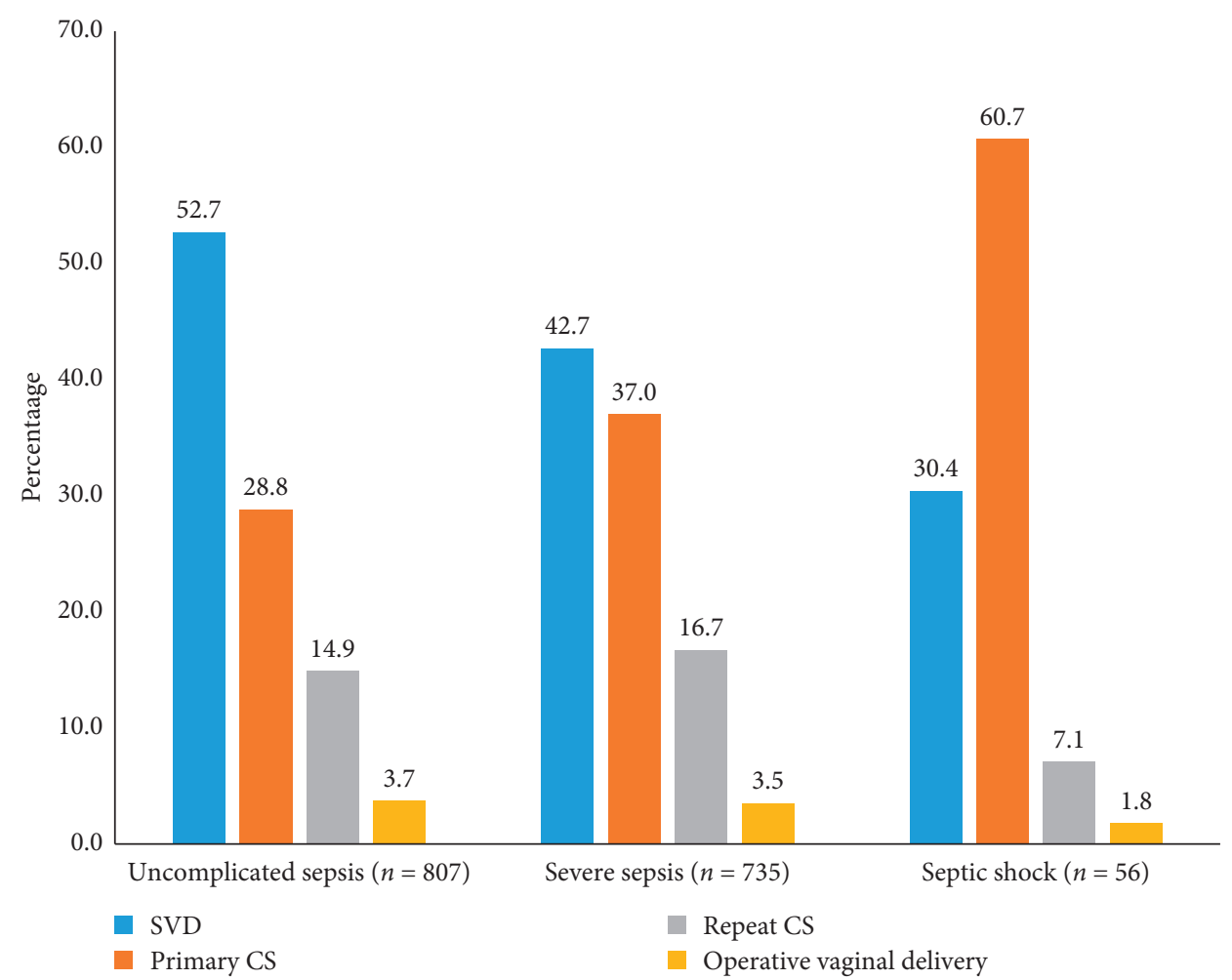

Figure 2: The relative risk of operative vaginal delivery to maternal sepsis as compared to other modes of delivery, redeveloped from Acosta et al.'s study 3 ( $P$ values for uncomplicated sepsis, severe sepsis, and septic shock in relation to mode of delivery were $<0.0001,0.001$, and 0.006 , respectively) $(N=1,622,474)$.

In Gommesen et al.'s study [7], the overall risks of maternal infection and perineal wound dehiscence were $5.8 \%$ and $15.3 \%$, respectively. The odds of maternal infection and perineal wound dehiscence in the episiotomy group were almost 3-fold and 1.6-fold higher than their counterparts. The risk of postpartum infection in $3^{\text {rd }} / 4^{\text {th }}$ degree perineal tear was three-times less than $2^{\text {nd }}$ degree tear; the common use of antibiotic prophylaxis in $3^{\text {rd }} / 4^{\text {th }}$ degree tears was attributed to the observed reduction. Perineal wound dehiscence was also by $68 \%$ less common among women who were given any antibiotic.

Axelsson et al.'s study reported that out of 795,072 deliveries at term, $11.7 \%$ women had infection in the postpartum period. Specifically, the risks of wound infection, 


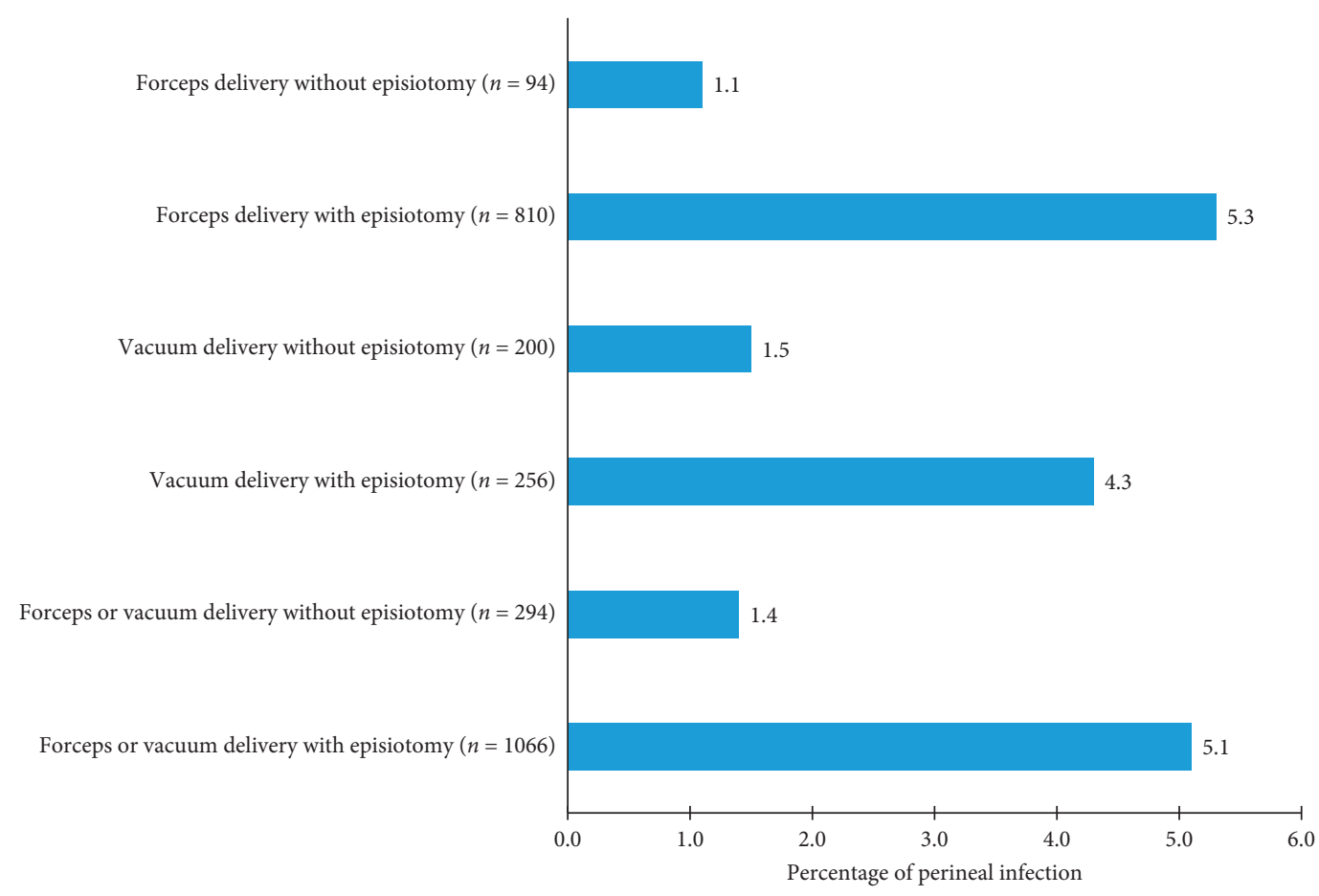

FIGURE 3: The relative risk of operative vaginal delivery to perineal infection as compared to episiotomy, redeveloped from Macleod et al.'s study (adjusted OR and 95\% CI for vacuum and forceps with episiotomy were reported as 2.9 (0.81-10.71) and 5.2 (0.71-38.31); for all forceps and vacuum deliveries with episiotomy, $P=0.002$ ).

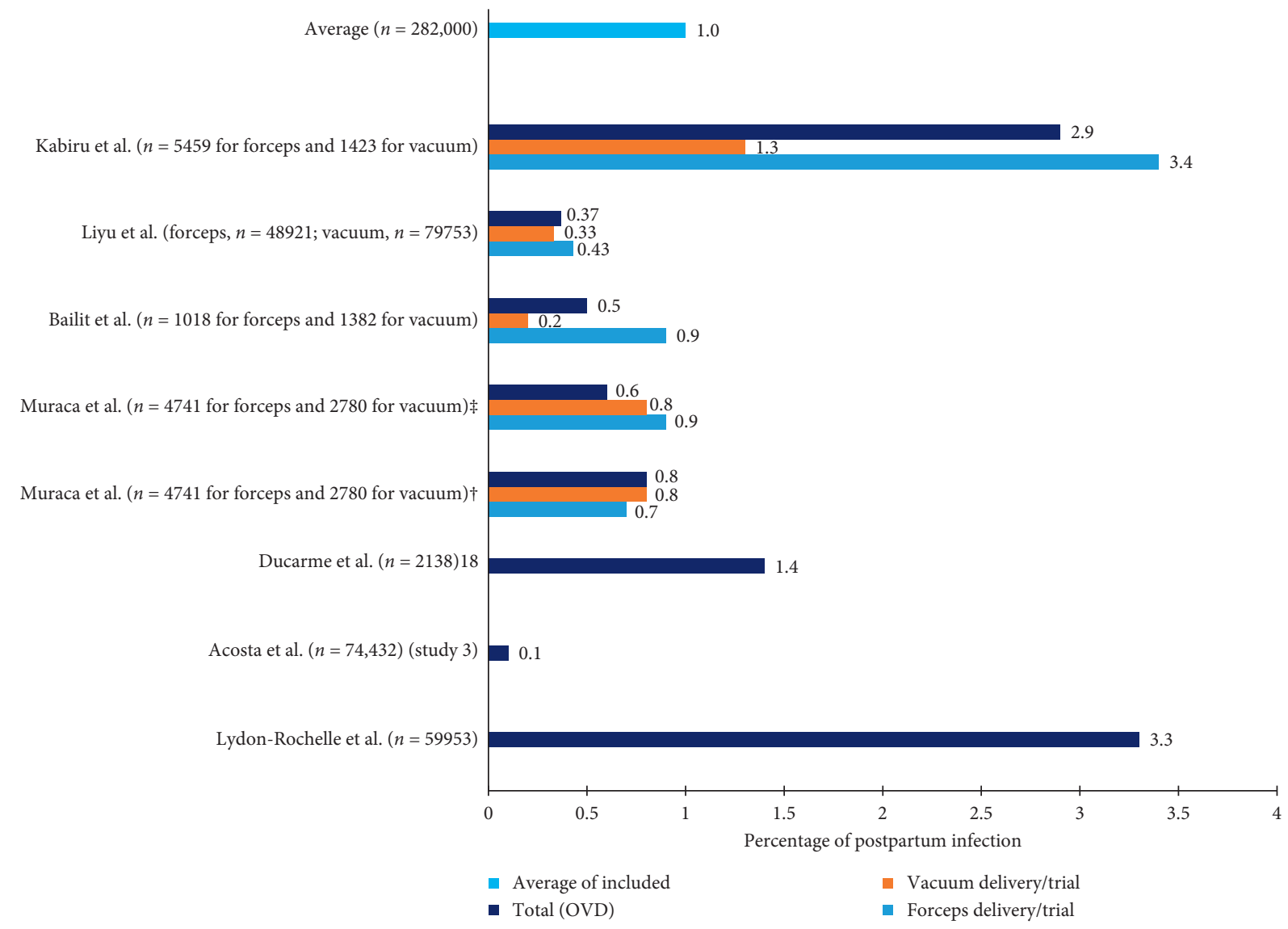

FIGURE 4: The proportion of postpartum infection (absolute risk) in large sample size studies among women for whom operative vaginal deliveries (OVD) were provided $[17,19,20,22] .{ }^{\dagger}$ Women with dystocia and prolonged second stage; ${ }^{\ddagger}$ women with fetal distress and prolonged second stage. 
endometritis, and urinary tract infection were $0.5 \%, 1.5 \%$, and $0.2 \%$, respectively. OVD was done for 65,991 (8.3\%) deliveries. The distribution of wound infection, endometritis, and urinary tract infection by OVD was $0.8 \%, 1.8 \%$, and $0.5 \%$, respectively. The risk of endometritis was lower by 1.6-fold than CS. For seventeen variables (including OVD and CS), the statistical test was done against the gestational age of 37-40 weeks, for which almost all showed highly statistically significant association in both crude and adjusted analysis [2]. We are not clear why term pregnancy was taken as a reference for all the variables as a risk factor for infection.

Another study that has shown the extremely low incidence of major puerperal infection among readmitted postpartum women was reported by Liyu et al. [25]. The incidence rates among women who delivered by SVD, vacuum, forceps, and CS were $0.27 \%, 0.33 \%, 0.43 \%$, and $0.45 \%$. The relative risk (SVD as reference), however, has shown that puerperal infection was weakly associated with vacuum $(\mathrm{OR}=1.2)$ and moderately associated with forceps $(\mathrm{OR}=1.6)$ and $\mathrm{CS}(\mathrm{OR}=1.8)$. In Berghella and Bellussi's study [26], the incidence rates of uterine infection in the SVD, OVD, and CS were $2.9 \%, 3.3 \%$, and 5.2\%, respectively, which were again weakly significant for OVD $(\mathrm{OR}=1.2)$ and strongly significant for CS $(\mathrm{OR}=5.2)$.

Two case-control studies were included to show the contribution of OVD to the selected cases among the different modes of delivery. Acosta et al.'s study 1 has shown that out of 89 uncomplicated sepsis cases, $32.6 \%, 19.1 \%$, and $48.3 \%$ accounted for SVD, OVD, and CS, respectively. In the control group, the distribution of SVD, OVD, and CS was $14.3 \%, 21.4 \%$, and $64.3 \%$, respectively. The unadjusted OR and adjusted OR with 95\% CIs for OVD were reported as $1.13(0.59-2.15)$ and $2.20(1.02-4.87)$, respectively [17]. But we could not understand how the AOR reported as statistically significant with the given data (taking SVD as a reference) and OVD was interpreted as a risk factor for uncomplicated maternal sepsis. The proportion of severe sepsis among OVDs was 1.5-fold higher and 3-fold less than SVD and CS cases, respectively, but was not statistically significant.

Similarly, Acosta et al.'s study 2 reported that the proportion of OVD in cases/severe sepsis and controls was $14.5 \%$ and $13.3 \%$, respectively. In the same category, the case/control distribution of SVD, elective CS, and emergency CS was $25.5 \% / 58.8 \%, 22 \% / 15.8 \%$, and $38 \% / 12.2 \%$, respectively. The UOR and AOR with $95 \% \mathrm{CIs}$ for OVD were reported as $2.52(1.52-4.17)$ and 2.49 (1.32-4.70), respectively [18]. We posed here as well the same question: how the statistical test showed statistical significance for OVD as a risk factor while the proportion was lower than SVD and CS, and with little difference between cases and controls? Interestingly, in both study 1 and $2[17,18]$, the proportion of the overall maternal sepsis among women delivered assisted by instruments was much lower than SVD and CS (19.4\% and $14.5 \%)$.

The subgroup meta-analysis could not also show statistically significant association in both these two studies (Figure 5). Similarly, the risk of postpartum infection among women who delivered by OVD as compared with other modes of delivery (the last row of subgroup meta-analysis) was not significant.

Weak association of OVD with postpartum infection was observed in the SVD vs OVD subgroup meta-analysis $(\mathrm{OR}=0.8 ; 95 \% \mathrm{CI}, 0.66-0.96)$. The odds of postpartum infection in women who delivered by CS were close to 2-fold higher than OVD $(\mathrm{OR}=1.9 ; 95 \% \mathrm{CI}, 1.52-2.45)$. The pooled meta-analysis demonstrated that the majority of postpartum infection occurred in the non-OVD groups (OR $=1.4 ; 95 \%$ CI, 1.12-1.78). With the exclusion of CS vs OVD studies (as sensitivity analysis), there was no statistical significant difference in the pooled meta-analysis $(\mathrm{OR}=0.89 ; 95 \% \mathrm{CI}$, 0.75-1.05).

\section{Discussion}

This review and meta-analysis could not find a substantial evidence from either the randomized controlled trial or observational studies to routinely use prophylactic antibiotics at OVD. The analysis clearly demonstrated the increased risk of postpartum infection after OVD when the procedure was accompanied by surgical or traumatic injury to the perineal area.

Knight and colleagues recommended to WHO, the UK, North America, and Australia to change their guidelines (which neither recommends antibiotic prophylaxis at OVD) by stating that a single dose of prophylactic antibiotic at OVD has reduced the risk of maternal infection by about half [14]. Berghella and Bellussi's comment on this study was quite positive and persuasive; they expressed their view as the study finding is a "practice-changing data" [27]. American College of Obstetricians and Gynecologists (ACOG) abstract has also concluded positively by stating that this trial provides robust evidence for the use of routine prophylactic antibiotics at OVD [28].

However, as the subgroup analysis of that particular study showed, cases which had shown statistically significant difference in the antibiotic group were perineal wound infections, wound breakdown, and ever too painful perineum, for which the episiotomy and perineal tear wound were the main risk factors, not the OVD per se. Had the investigators done multivariate analysis of maternal infection in the intervention and placebo group taking OVD, episiotomy, and perineal tear as independent variables, only the latter two would have shown a statistically significant association.

The finding of comparative result between the two groups in nonperineal wound infection, endometritis, and maternal infection other than wound breakdown reaffirms the significance of surgical and traumatic perineal wound for the increased risk of perineal wound infection and the importance of prophylactic antibiotic at OVD accompanied by perineal trauma. Although perineal wound infection and wound breakdown were reported with different absolute figure, our argument is that, until proved otherwise, almost all wound breakdown cases were due to episiotomy and perineal tear wound infection, predisposed by the surgical and traumatic wound, not merely by the applied instruments. 


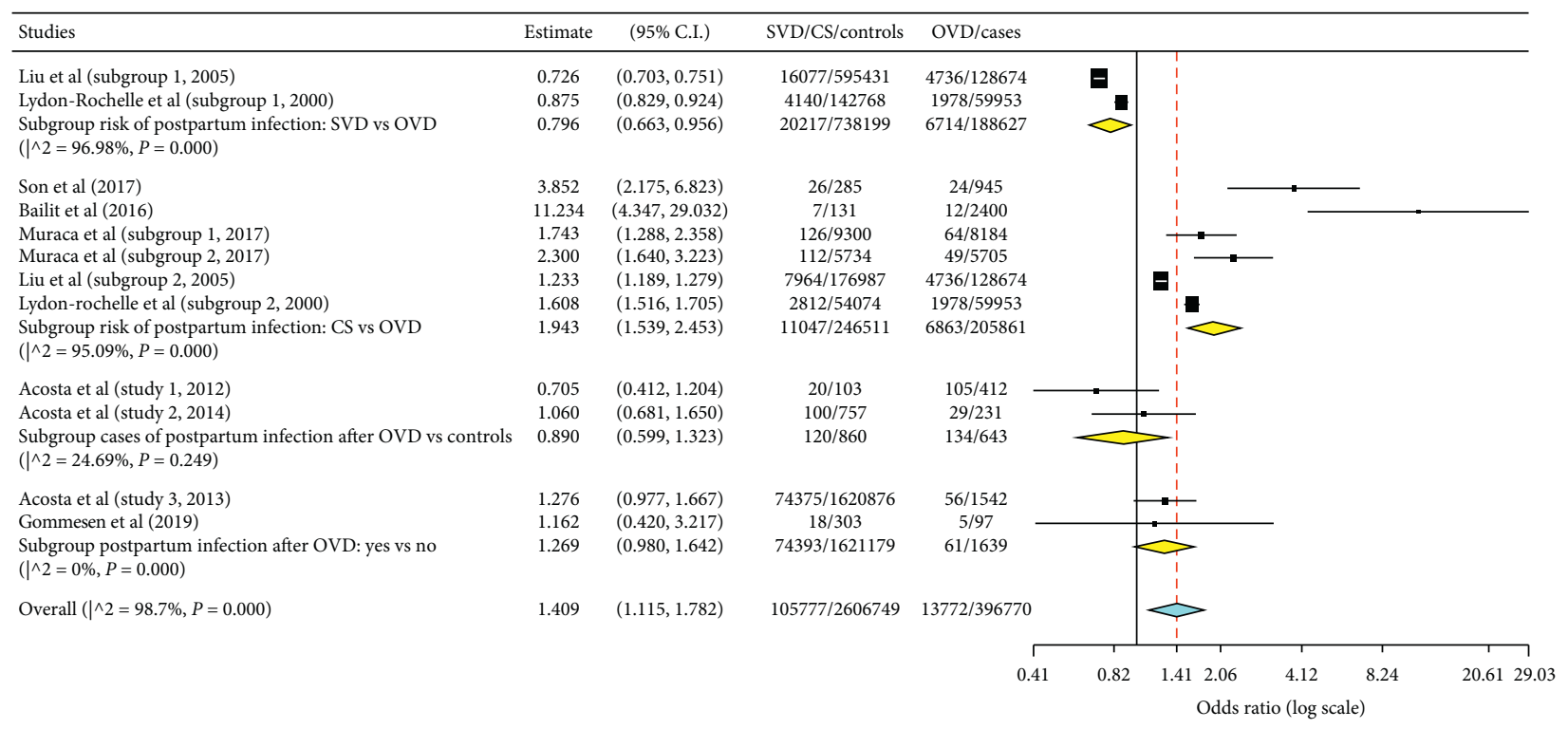

FIGURE 5: Subgroup meta-analysis of postpartum infection risk after operative vaginal delivery (OVD) in comparison with spontaneous vaginal delivery (SVD) and caesarean section (CS) delivery. The subgroup meta-analysis was done for SVD vs OVD, CS vs OVD, and the contribution of OVD to cases or postpartum infection.

In line with this, a Cochrane review defined episiotomy wound dehiscence as wound infection [29]. A recent prospective cohort study from Denmark has also shown the complications of OVD (increased risk of perineal tears) and episiotomy (3-fold increased risk of infection/wound dehiscence) [7]. The point is nearly all the study participants included in this trial had one or more much higher risk factors for postpartum infection than instrument application, which were not corrected by randomization or multivariate analysis.

In our opinion, this is enough evidence to deduce that the study [14] was actually a comparison of antibiotic prophylaxis with placebo in women with episiotomy and perineal tear wound, as $97 \%$ of the study participants had either one or both and as the bivariate statistical tests clearly demonstrated the significant association with only perineal wound infection, perineal wound breakdown, and ever too painful perineum.

Whether to give antibiotic prophylaxis or not in women with episiotomy is one of the controversial issues in obstetrics; WHO, ACOG, and others are against it [30-33]; a Cochrane review weakly recommended it [34]. This study [14], however, has demonstrated the statistically significant difference in wound breakdown and perineal wound infection between the intervention and the placebo group, which is an important finding to consider prophylactic antibiotic after episiotomy and perineal tear.

Nevertheless, it would have been good if the statistical analysis was not limited only to bivariate analysis; although it is a randomized trial which gave equal chance to the potential confounders other than the perineal wound, multivariate analysis could have been better to further control the confounders and increase the strength of evidence, particularly in light of multiple risk factors for perineal wound infection.
With the exception of Gommesen et al.'s study [7], other studies included in this review as well assessed the risk of postpartum infection mainly by comparing OVD with other modes of delivery without adjusting to the surgical and traumatic perineal wound; some authors even tempted to use prophylactic antibiotics at OVD [17]. The condition was that many of the OVDs used to require episiotomy and got complicated with perineal tear. Such interconnectedness of interventions and associated traumatic complication was probably the main reason for wrongly attributing postpartum infection to OVD. A literature review by Kamel and Khaled overemphasized the association of postpartum infection with OVD without giving emphasis to the commonly associated episiotomy and perineal tear [35].

Acosta et al.'s study [16], however, has shown about 3fold and 5-fold independent association of perineal infection in women who delivered assisted by vacuum or forceps after episiotomy, respectively. In their study, the incidence of perineal infection after forceps and vacuum delivery without episiotomy was extremely low. Those who developed perineal infection without episiotomy were those who had perineal tear, as perineal infection in intact perineum is very unlikely. Although the sample size was relatively small, Gommesen et al.'s study also clearly showed the absence of statistically significant association of OVD with postpartum infection. The meta-analysis finding in this study is consolidating evidence to the above arguments.

Above all, the extremely low absolute risk of postpartum infection (on average 1\%) at OVD in many of the large sample size studies which had reported the incidence of postpartum infection over three decades and the very weak relative risk in a few studies $[2,25]$ are not robust evidence to consider prophylactic antibiotic at OVD without perineal wound. This is because antibiotic prophylaxis at OVD and antibiotic prophylaxis at episiotomy and perineal tear are 
different clinical settings. The essence is that as all OVDs do not require episiotomy and do not complicate with a perineal tear as shown in some of the included studies $[16,20,21]$, there is no supporting evidence to routinely administer prophylactic antibiotic for mere application of instruments to assist vaginal delivery.

In the included clinical trial [14], the highly increased absolute risks of maternal infection and wound breakdown in both antibiotic and placebo groups (more than 10-fold of the incidence of cohort studies) were probably due to the fact that almost every study participant had either episiotomy, perineal tear, or both. In other words, instrument assisted delivery is known to increase the risk of perineal tear and genital laceration, but not directly and necessarily mean that it increases wound infection.

Episiotomy and perineal tear wound infections can occur without instrument-assisted vaginal delivery [36]; although reported data showed contradictory results, increased risk of perineal wound infection is because of iatrogenic or natural birth injury to the genital tract, which is susceptible to contamination by the normal flora of the birth canal and anal canal [37]. A prospective multicenter study has also showed that the source of bacteria for antepartum, intrapartum, and postpartum maternal infection was the genital tract in $61 \%$ of patients, predominantly Escherichia coli, followed by Group B Streptococcus [38].

Therefore, the available scientific data this time around do not have the leverage to change the existing guidelines and practice at OVD without episiotomy and without a perineal tear. Routine use of prophylactic antibiotic at OVD may unnecessarily increase the risk of antibiotic resistance, as the high incidence of infection noted in the clinical trial and progressively increasing nonsusceptibility of the commonest bacterial etiology (Escherichia coli) of postpartum infection to amoxicillin and clavulanic acid were reported [39].

The increased risks of perineal wound infection and perineal wound breakdown in both the randomized clinical trial and cohort studies are, however, indicative data to consider prophylactic antibiotic for episiotomy and perineal tear until another clinical trial proved it otherwise.

We recommend that the clinical trial with antibiotic prophylaxis at OVD has to be done in women without iatrogenic or natural genital trauma with a hypothesis of introducing bacteria while applying instruments can increase the risk of postpartum maternal infection. Otherwise, in the presence of an already established risk factor for maternal infection (major epithelial and muscle breakdown requiring repair in the perineal area), attributing OVD to it sounds little and will not convince clinicians to change their current practice.

One of the limitations of this review was lack of clinical trial investigating the risk of OVD to postpartum infection without perineal trauma. The second is the majority of the included studies did not include episiotomy and perineal tear as independent variables for multivariate analysis.

In conclusion, both the relative and absolute risks of postpartum infection at OVD are extremely lower than the caesarean delivery and delivery accompanied by episiotomy and $3^{\text {rd }} / 4^{\text {th }}$ degree perineal tear. Thus, from previous studies, there is no subtantial evidence to use prophylatic antibiotic at OVD, but women with episiotomy and perineal tear can benefit from prophylactic antibiotic administration.

\section{Conflicts of Interest}

The authors declare that they have no conflicts of interest.

\section{Authors' Contributions}

All authors contributed equally.

\section{Supplementary Materials}

PRISMA checklist and STROBE check list. (Supplementary Materials)

\section{References}

[1] P. Ahnfeldt-Mollerup, L. K. Petersen, J. Kragstrup, R. D. Christensen, and B. Sørensen, "Postpartum infections: occurrence, healthcare contacts and association with breastfeeding," Acta Obstetricia et Gynecologica Scandinavica, vol. 91, no. 12, pp. 1440-1444, 2012.

[2] D. Axelsson, J. Brynhildsen, and M. Blomberg, "Postpartum infection in relation to maternal characteristics, obstetric interventions and complications," Journal of Perinatal Medicine, vol. 46, no. 3, pp. 271-278, 2018.

[3] J. Ngonzi, L. M. Bebell, Y. Fajardo et al., "Incidence of postpartum infection, outcomes and associated risk factors at mbarara regional referral hospital in Uganda," BMC Pregnancy Childbirth, vol. 18, no. 1, p. 270, 2018.

[4] L. French, "Prevention and treatment of postpartum endometritis," Current Women's Health Reports, vol. 3, no. 3, pp. 274-279, 2003.

[5] R. A. Leth, J. K. Møller, R. W. Thomsen, N. Uldbjerg, and M. Nørgaard, "Risk of selected postpartum infections after cesarean section compared with vaginal birth: a five-year cohort study of 32,468 women," Acta Obstetricia et Gynecologica Scandinavica, vol. 88, no. 9, pp. 976-983, 2009.

[6] F. M. Smaill and R. M. Grivell, "Antibiotic prophylaxis versus no prophylaxis for preventing infection after cesarean section," Cochrane Database of Systematic Reviews, vol. 10, no. 1, Article ID CD007482.

[7] D. Gommesen, E. A. Nohr, H. C. Drue, N. Qvist, and V. Rasch, "Obstetric perineal tears: risk factors, wound infection and dehiscence: a prospective cohort study," Archives of Gynecology and Obstetrics, vol. 300, no. 1, pp. 67-77, 2019.

[8] WHO, WHO Recommendations for Prevention and Treatment of Maternal Peripartum Infections, WHO, GENEVA, Switzerland, 2015, http://www.who.int/reproductivehealth/.

[9] J. Van Schalkwyk and N. Van Eyk, "No. 247-antibiotic prophylaxis in obstetric procedures," Journal of Obstetrics and Gynaecology Canada, vol. 39, no. 9, pp. e293-e299, 2017.

[10] RANZCOG, Prophylactic Antibiotics in Obstetrics and Gynecology, RANZCOG, Brisbane, Australia, 2016, https://ranzcog.edu.au.

[11] RCOG, "Operative vaginal delivery," RCOG, London, UK, 2011, https://www.rcog.org.uk/en/guidelines-researchservices/guidelines/gtg26/.

[12] B. A. Armson, "Is planned cesarean childbirth a safe alternative?" Canadian Medical Association Journal, vol. 176, no. 4, pp. 475-476, 2007. 
[13] T. Liabsuetrakul, T. Choobun, K. Peeyananjarassri, and Q. M. Islam, "Antibiotic prophylaxis for operative vaginal delivery," Cochrane Database of Systematic Reviews, vol. 8, Article ID CD004455, 2017.

[14] M. Knight, V. Chiocchia, C. Partlett et al., "Prophylactic antibiotics in the prevention of infection after operative vaginal delivery (anode): a multicentre randomised controlled trial," The Lancet, vol. 393, no. 10189, pp. 2395-2403, 2019.

[15] E. von Elm, D. G. Altman, M. Egger, S. J. Pocock, P. C. Gøtzsche, and J. P. Vandenbroucke, "The strengthening the reporting of observational studies in epidemiology (STROBE) statement: guidelines for reporting observational studies," Journal of Clinical Epidemiology, vol. 61, no. 4, pp. 344-349, 2008.

[16] M. Macleod, B. Strachan, R. Bahl, L. Howarth, K. Van De Venne, and D. Murphy, "A prospective cohort study of maternal and neonatal morbidity in relation to use of episiotomy at operative vaginal delivery," BJOG: An International Journal of Obstetrics \& Gynaecology, vol. 115, no. 13, pp. 1688-1694, 2008.

[17] C. Acosta, S. Bhattacharya, D. Tuffnell, J. Kurinczuk, and M. Knight, "Maternal sepsis: a Scottish population-based case-control study," BJOG: An International Journal of $\mathrm{Ob}$ stetrics \& Gynaecology, vol. 119, no. 4, pp. 474-483, 2012.

[18] C. D. Acosta, J. J. Kurinczuk, D. N. Lucas, D. J. Tuffnell, S. Sellers, and M. Knight, "Severe maternal sepsis in the UK, 2011-2012: a national case-control study," PLoS Medicine, vol. 11, no. 7, Article ID e1001672, 2014.

[19] C. D. Acosta, M. Knight, H. C. Lee, J. J. Kurinczuk, J. B. Gould, and A. Lyndon, "The continuum of maternal sepsis severity: incidence and risk factors in a population-based cohort study," PLoS ONE, vol. 8, no. 7, Article ID e67175, 2013.

[20] W. N. Kabiru, D. Jamieson, W. Graves, and M. Lindsay, "Trends in operative vaginal delivery rates and associated maternal complication rates in an inner-city hospital," American Journal of Obstetrics and Gynecology, vol. 184, no. 6, pp. 1112-1114, 2001.

[21] J. L. Bailit, W. A. Grobman, M. M. Rice et al., "Evaluation of delivery options for second-stage events," American Journal of Obstetrics and Gynecology, vol. 214, no. 5, p. 638, 2016.

[22] G. M. Muraca, Y. Sabr, S. Lisonkova et al., "Perinatal and maternal morbidity and mortality after attempted operative vaginal delivery at midpelvic station," Canadian Medical Association Journal, vol. 189, no. 22, pp. E764-E772, 2017.

[23] M. Son, A. Roy, and W. A. Grobman, "Attempted operative vaginal delivery vs repeat cesarean in the second stage among women undergoing a trial of labor after cesarean delivery," American Journal of Obstetrics and Gynecology, vol. 216, no. 4, 2017.

[24] G. Ducarme, J.-F. Hamel, P.-E. Bouet, G. Legendre, L. Vandenbroucke, and L. Sentilhes, "Maternal and neonatal morbidity after attempted operative vaginal delivery according to fetal head station," Obstetrics \& Gynecology, vol. 126, no. 3, pp. 521-529, 2015.

[25] M. Lydon-Rochelle, V. L. Holt, D. P. Martin, and T. R. Easterling, "Association between method of delivery and maternal rehospitalization," JAMA, vol. 283, no. 18 , pp. 2411-2416, 2000.

[26] S. Liu, M. Heaman, K. S. Joseph et al., "Risk of maternal postpartum readmission associated with mode of delivery," Obstetrics \& Gynecology, vol. 105, no. 4, pp. 836-842, 2005.

[27] V. Berghella and F. Bellussi, "Antibiotics for operative vaginal delivery: practice-changing data," The Lancet, vol. 393, no. 10189, pp. 2361-2362, 2019.
[28] ACOG, Prophylactic Antibiotics for the Prevention of Infection Following Operative Vaginal Delivery: the Anode Trial, ACOG, Washington, DC, USA, 2019, https://www.ajog.org.

[29] M. Bonet, E. Ota, C. E. Chibueze, and O. T. Oladapo, "Routine antibiotic prophylaxis after normal vaginal birth for reducing maternal infectious morbidity," Cochrane Database of Systematic Reviews, vol. 11, Article ID CD012137, 2017.

[30] WHO Reproductive Health Library, WHO Recommendation on Routine Antibiotic Prophylaxis for Episiotomy, WHO Reproductive Health Library, Geneva, Switzerland, 2015, https://extranet.who.int.

[31] American College of Obstetricians and Gynecologist, "ACOG practice bulletin no. 120: use of prophylactic antibiotics in labor and delivery," Obstetrics \& Gynecology, vol. 117, no. 6, pp. 1472-1483, 2011.

[32] National Institute for Health and Care Excellence, Intrapartum Care: Care of Healthy Women and Their Babies during Childbirth, National Institute for Health and Care Excellence, London, UK, 2014, http://www.nice.org.uk/guidance/cg190.

[33] A. Chandrababu, S. Kumar, and A. Goli, "Antibiotic prophylaxis with episiotomy-is it necessary?" MGM Journal of Medical Sciences, vol. 6, no. 1, pp. 19-21, 2019.

[34] M. Bonet, E. Ota, C. E. Chibueze, and O. T. Oladapo, “Antibiotic prophylaxis for episiotomy repair following vaginal birth," Cochrane Database of Systematic Reviews, vol. 11, Article ID CD012136, 2017.

[35] O. Mohammed-Ahmed, K. Hinshaw, and M. Knight, "Operative vaginal delivery and post-partum infection," Best Practice and Research Clinical Obstetrics and Gynaecology, vol. 56, pp. 93-106, 2019.

[36] A. Kamel and M. Khaled, "Episiotomy and obstetric perineal wound dehiscence: beyond soreness," Journal of Obstetrics and Gynaecology, vol. 34, no. 3, pp. 215-217, 2014.

[37] A. W. Wong and A. J. Rosh, "Postpartum infection," 2018, https://emedicine.medscape.com.

[38] S. Knowles, N. O’Sullivan, A. Meenan, R. Hanniffy, and M. Robson, "Maternal sepsis incidence, aetiology and outcome for mother and fetus: a prospective study," BJOG: An International Journal of Obstetrics \& Gynaecology, vol. 122, no. 5, pp. 663-671, 2015.

[39] J. Oteo, J. Campos, E. Lázaro et al., "Increased amoxicillinclavulanic acid resistance in Escherichia coli blood isolates, Spain," Emerging Infectious Diseases, vol. 14, no. 8, pp. 1259-1262, 2008. 